\title{
GATA4 is a negative regulator of contractility in mouse testicular peritubular myoid cells
}

\author{
Yu-Qian Wang ${ }^{1,2}$, Aalia Batool ${ }^{1,2}$, Su-Ren Chen ${ }^{1}$ and Yi-Xun Liu ${ }^{1}$ \\ ${ }^{1}$ State Key Laboratory of Stem Cell and Reproductive Biology, Institute of Zoology, Chinese Academy of Sciences, \\ Beijing, China and ${ }^{2}$ University of Chinese Academy of Sciences, Beijing, China
}

Correspondence should be addressed to S-R Chen or Y-X Liu; Email: chensuren@ioz.ac.cn or liuyx@ioz.ac.cn

\begin{abstract}
Reduced contractility of the testicular peritubular myoid (PTM) cells may contribute to human male subfertility or infertility. Transcription factor GATA4 in Sertoli and Leydig cells is essential for murine spermatogenesis, but limited attention has been paid to the potential role of GATA4 in PTM cells. In primary cultures of mouse PTM cells, siRNA knockdown of GATA4 increased the contractile activity, while GATA4 overexpression significantly attenuated the contractility of PTM cells using a collagen gel contraction assay. Using RNA sequencing and qRT-PCR, we identified a set of genes that exhibited opposite expressional alternation between Gata4 siRNA vs nontargeting siRNA-treated PTM cells and Gata4 adenovirus vs control adenovirus-treated PTM cells. Notably, ion channels, smooth muscle function, cytokines and chemokines, cytoskeleton, adhesion and extracellular matrix were the top four enriched pathways, as revealed by cluster analysis. Natriuretic peptide type B (NPPB) content was significantly upregulated by GATA4 overexpression in both PTM cells and their culture supernatant. More importantly, the addition of $100 \mu M$ NPPB could abolish the promoting effect of Gata4 silencing on PTM cell contraction. Taken together, we suggest that the inhibitory action of GATA4 on PTM cell contraction is mediated at least partly by regulating genes belonging to smooth muscle contraction pathway (e.g. Nppb).

Reproduction (2018) 156 343-351
\end{abstract}

\section{Introduction}

Spermatogenesis is fundamental to the establishment and maintenance of male fertility, while abnormal spermatogenesis will lead to male infertility/subfertility or various testicular tumors. It is generally considered that mammalian spermatogenesis is a complex sequential process of germ cell differentiation from primordial germ cells or spermatogonial stem cells (SSCs) to functional haploid sperm (Chen \& Liu 2015, Chen et al. 2016c). In addition to germ cell development, spermatogenesis requires significant contributions of somatic cell populations, including testicular Sertoli cells, Leydig cells, peritubular myoid (PTM) cells, blood vessels and macrophages (Rebourcet et al. 2014, DeFalco et al. 2015). The importance of Sertoli cells, Leydig cells and macrophages in spermatogenesis has been fully revealed via cell ablation strategy and conditional knockout mouse models (Rebourcet et al. 2014, DeFalco et al. 2015). However, the regulatory roles and mechanism of PTM cells in testis development and spermatogenesis remain largely unknown.

PTM cells are the main cellular components of the wall of seminiferous tubules. They possess smooth musclelike characteristics and are thought to be important for the intratesticular transport of immotile sperm. Loss of contractility (phenotypical switch) in human PTM cells may contribute to sub- or infertility, because PTM cell markers, such as myosin heavy chain (MYH11) and alpha smooth muscle actin ( $\alpha-S M A)$ are often lost or diminished in PTM cells of men with impaired spermatogenesis (Schell et al. 2010, Welter et al. 2013). Recent studies have shown that several PTM cell-expressed genes, such as colony-stimulating factor 1 (CSF1) (Oatley et al. 2009), androgen receptor (AR) (Welsh et al. 2009), leucine-rich repeat-containing G protein-coupled receptor 4 (LGR4) (Qian et al. 2013) and glial cell line-derived neurotrophic factor (GDNF) (Chen et al. 2014, 2016a), are essential for mouse spermatogenesis by knockout mouse models. Furthermore, contraction and relaxation of PTM cells are regulated by sympathetic innervation and paracrine and endocrine substances, including endothelin (EDN1, ET-1), angiotensin II (ANGII), platelet-derived growth factor (PDGF-BB), prostaglandin F2 $\alpha$ (PGF2 $\alpha$ ), neurotransmitters and hormones (Mayerhofer 2013). However, the overall role of PTM cells and individual function of PTM cellexpressed genes remain poorly understood; especially, the intrinsic genes/transcription factors that regulate the PTM cell contractility have been largely neglected.

Transcription factor GATA4 is an important regulator of spermatogenesis. In murine Leydig cells, GATA4 regulates steroidogenesis and glycolysis (Bergeron et al. 2015, Schrade et al. 2015). Our previous study suggests that GATA4 in Sertoli cells is vital for establishment and 
maintenance of the SSC pool by attenuating chemokine signaling, taking advantage of conditional knockout mice (Chen et al. 2015). Regulation of chemokines by GATA4 is further proved by a microarray-based gene expression study (Schrade et al. 2016). In addition to Leydig and Sertoli cells, GATA4 is expressed in the nuclei of PTM cells. However, the potential role of GATA4 (both in vitro and in vivo) in PTM cell population remains unknown.

Here, we assessed the impact of Gata4 knockdown and overexpression on primary cultures of adult mouse PTM cells. Using a functional assay and complementary transcriptome analysis, we show that GATA4 negatively regulates PTM cell contraction, involving its target genes implicated in ion channels and smooth muscle function. Our in vitro study will provide the solid basic data for exploring the role of GATA4 in PTM cells and spermatogenesis using conditional knockout mice.

\section{Materials and methods}

\section{Animals}

C57BL/6J male mice were obtained from Vital River Laboratory (Beijing, China). All animal work was approved by the Institutional Animal Care and Use Committee of Institute of Zoology, Chinese Academy of Sciences.

\section{Primary PTM cell isolation and culture}

The PTM cell isolation protocol was mainly adopted from Chen et al. (2014). Briefly, PTM cells were isolated from 10-week-old C57BL/6J male mice. Enzyme digestion 1: tunica albuginea was removed and digested with $1 \mathrm{mg} / \mathrm{mL}$ Collagenase4 (Sigma-Aldrich) and $1 \mathrm{mg} / \mathrm{mL}$ DNase1 (SigmaAldrich) in PBS solution at $34^{\circ} \mathrm{C}$ in a water bath for $15 \mathrm{~min}$ and washed three times with PBS to remove interstitial cells. Enzyme digestion 2: the remaining seminiferous tubules were further digested with $1 \mathrm{mg} / \mathrm{mL}$ Collagenase 4 and $1 \mathrm{mg} /$ $\mathrm{mL}$ DNase1 in PBS for $20 \mathrm{~min}$ at $34^{\circ} \mathrm{C}$ to release PTM and other cells. After precipitation, supernatant was collected and centrifuged for $10 \mathrm{~min}$ at $600 \mathrm{~g}$. Cells were resuspended in DMEM/F12, applied to the top of a Percoll (Sigma-Aldrich) step gradient (differing by 5\% from 20 to $60 \%$ Percoll) and centrifuged at $4{ }^{\circ} \mathrm{C}$ for $20 \mathrm{~min}$ at $800 \mathrm{~g}$. Most PTM cells were located at the $35-40 \%$ Percoll interface. The isolated PTM cells were cultured in DMEM/F12 containing $10 \%$ fetal bovine serum (FBS) (BD Biosciences, CA, USA) at $37^{\circ} \mathrm{C}$ with $5 \% \mathrm{CO}_{2}$. The purity was determined by immunocytofluorescense with an antibody of PTM cell marker $\alpha$-SMA (Abcam, ab5694).

\section{SiRNA transfection and adenovirus infection}

For GATA4 knockdown, primary PTM cells were transiently transfected with a pool of four siRNAs targeting mouse Gata4 (5'-AGAGAAUAGCUUCGAACCA-3', 5'-GGAUAUG GGUGUUCCGGGU-3', 5'-CUGAAUAAAUCUAAGACGC-3', 5'-GGACAUAAUCACCGCGUAA-3') or with nontargeting control siRNA (5'-UGGUUUACAUGUCGACUAA-3'; all from
GenePharma, Shanghai, China) using Lipofectamine 2000 (Invitrogen) at a final concentration of $0.1 \mu \mathrm{M}$. The cells were harvested at $48 \mathrm{~h}$ after transfection for RNA sequencing and qRT-PCR analysis. To overexpress GATA4, the PDV4 adenovirus containing mouse Gata4 cDNA (1329bp) was generated by GenePharma. Viral constructs were transduced into a 293T cell line, and a high titer $\left(10^{10} \mathrm{IU} / \mathrm{mL}\right)$ of viral particles was obtained by four rounds of amplification. PTM cells were infected with Gata4-adenovirus (20 pfu/cell) and analyzed via qRT-PCR after $24 \mathrm{~h}$. GenePharma green fluorescent protein (Ad-GFP) served as a negative control.

\section{RNA sequencing}

Total RNA (1 $\mu$ g for each samples) was extracted from Gata4 siRNA-, Gata4 adenovirus- and control oligonucleotide-treated PTM cells using TRIzol reagent (Tiangen, Beijing, China) as the manufacturer's instructions. Three duplicate samples for each treatment were included. Then, equal amounts of total RNA were analyzed using BGISEQ-500 platform (Fehlmann et al. 2016) and the sequencing procedure was performed by BGI (Shenzhen, China). The list of differentially expressed genes (with fold change cut-offs $\geq 2$ or $\leq 0.5$ and significance $P$ value $<0.05$ ) was provided as Supplementary Table 1 (see section on supplementary data given at the end of this article).

\section{Quantitative RT-PCR (qRT-PCR)}

Briefly, measurement of RNA integrity and synthesis of cDNA were performed as previously described (Chen et al. 2013). Each sample was measured in triple independent experiments. Samples CT values were normalized to Gapdh CT values and relative expression levels were calculated using the $\Delta \Delta C T$ method. Primer pairs were listed in Table 1.

\section{Immunostaining}

Mouse adult testes were harvested and fixed in $4 \%$ paraformaldehyde (PFA) overnight. Five-micron paraffinembedded sections were cut for staining. Immunostaining methods were performed as described (Li et al. 2013). The sections were incubated with the primary antibody of MYH11 (Abcam, ab53219) or GATA4 (Santa Cruz, sc-1237, TX, USA) at $4{ }^{\circ} \mathrm{C}$ overnight. For negative controls we incubated the sections with the corresponding IgG isotype instead of the antiserum. Fluorescent secondary antibodies were purchased from Cell Signaling Technology and nuclei were stained with DAPI (Beyotime, Shanghai, China). For immunohistochemistry, secondary and third antibodies were obtained from ZSGBBio (Beijing, China) and staining was visualized using a diaminobenzidine substrate kit (ZSGB-Bio).

\section{Collagen gel contraction assay}

Twenty-four hours after transfection with siRNA or adenovirus, PTM cells (without FBS) were used for a collagen contractility assay according to the manufacturer's instructions (Cell Biolabs, CA, USA). 2,3-Butanedione monoxime (Cell Biolabs), a cell contraction inhibitor, was used as a negative control. Pictures 
Table 1 Primers used for qRT-PCR.

\begin{tabular}{lll}
\hline Gene & Primer $\left(5^{\prime}-3^{\prime}\right)$ & \\
\hline Gata4 & CCCTACCCAGCCTACATGG & ACATATCGAGATTGGGGTGTCT \\
Kcnk12 & TCATCGCCTACGGACTGTTC & TGAAGAGCGAGTAGATGCAGC \\
Kcnq5 & GTCGGCGCAACGTCAAGTA & AACCAAACACAAGGAGAAAAACG \\
Atp $1 \mathrm{a} 3$ & TCTCAGATGTGTCCGTTCTTCT & TGGAAAGAGAGTGAAAGGCAAG \\
Nalcn & CAAAGATGCACATACGGGGAA & AAAGCCCGGATCATAATGAGTG \\
Nppb & GAGGTCACTCCTATCCTCTGG & AGGCGATTCCTCCGACTTTTCTC \\
Gpr 4 Ednrb & GCTGGGCGTCTACCTGATG & TCTTAGTGGGTGGCGTCATGTTG \\
Agt & GTGGCTTCTTGGGGGTATGG & CTTCTCATTCACAGGGGAGGT \\
Gapdh & TCTCCTTTACCACAACAAGAGCA & TGTAGACCATGTAGTTGAGGTCA \\
\hline
\end{tabular}

of free-floating collagen gel lattices were taken 2 days after release and analyzed with Imagej. The degree of contraction was evaluated by determining the area of the gel matrix before and after treatment.

\section{Enzyme-linked immunosorbent assay}

NPPB measurement from cell lysates and culture supernatant was performed using a mouse NPPB ELISA kit (JONLN, Shanghai, China), following the manufacturer's instructions. NPPB concentration $(\mathrm{pg} / \mathrm{mL})$ was determined by absorbance measurements at $450 \mathrm{~nm}$ against a standard curve in a competitive assay using an ELISA reader.

\section{Cell viability assay}

Cell viability was determined by counting the ratio of live cells to total cells after transfection by an automated cell counter (Thermo Fisher Scientific).

\section{Statistics}

Data were compared for statistical significance using GraphPad Prism version 5.01 (GraphPad Software Inc.). Student's $t$ tests were used for the analyses. The data were presented as the mean \pm S.E.M. of at least three independent experiments, and differences were considered statistically significant at $* P<0.05$ and $* * P<0.01$.

\section{Results}

\section{Exploring the role of GATA4 in primary mouse PTM cells using gain- and loss-of-function approaches}

To identify the expression pattern of GATA4 within mouse testes, we performed immunological staining of GATA4 and a PTM cell marker MYH11. In addition to Sertoli cells and Leydig cells, transcription factor GATA4 was specifically expressed in PTM cells (Fig. 1, arrowheads) at the periphery of seminiferous tubules within the testes. To investigate the role of GATA4 in this cell population, primary mouse PTM cells were isolated using Percoll discontinuous gradients and further identified by immunostaining of the PTM cell marker $\alpha$-SMA (Fig. 2A). Approximately 94\% of the isolated cells were $\alpha$-SMA positive, indicating that we obtained primary PTM cells with high purity (Fig. 2B). Next, we used siRNA and adenovirus to inhibit or overexpress
A
$8 w$

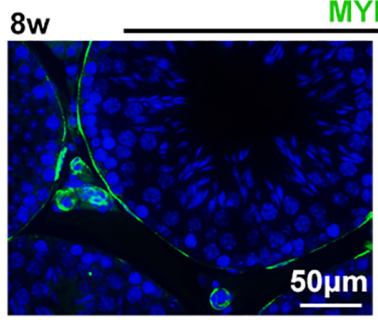

MYH11

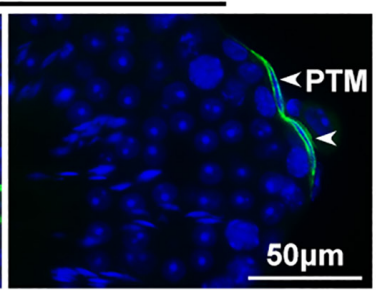

$B$

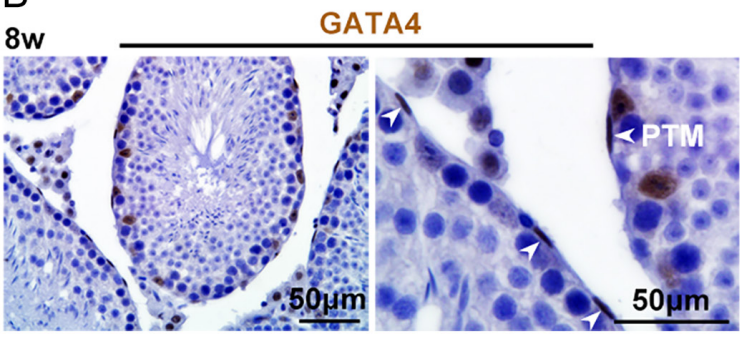

www.reproduction-online.org $\lg G$

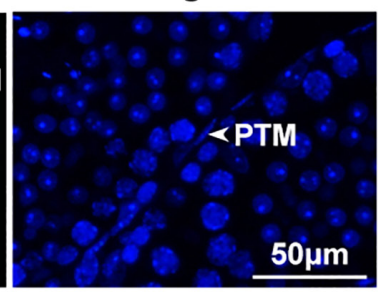

$\lg G$

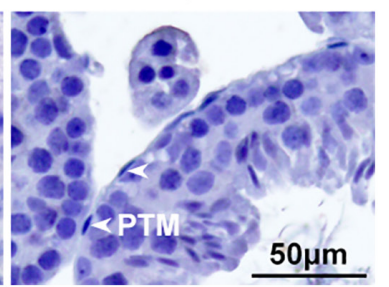

Figure 1 GATA4 localization in PTM cells within mouse adult testes. (A) Immunofluorescence staining for a PTM cell marker MYH11 (green signals) on the tissue sections of 8-week-old testes. Nuclei were stained with DAPI. (B) GATA4 detection by immunohistochemical staining (brown signals) in 8-week-old testis sections. Scale bar, $50 \mu \mathrm{m}$. Arrowheads indicate PTM cells at the periphery of seminiferous tubules. 
A

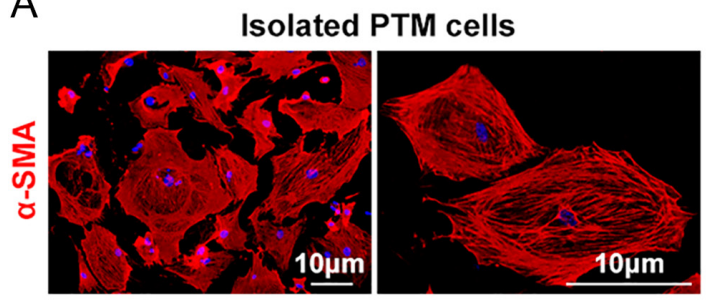

C

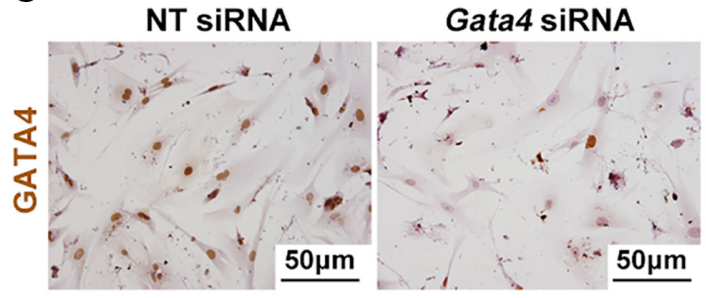

E

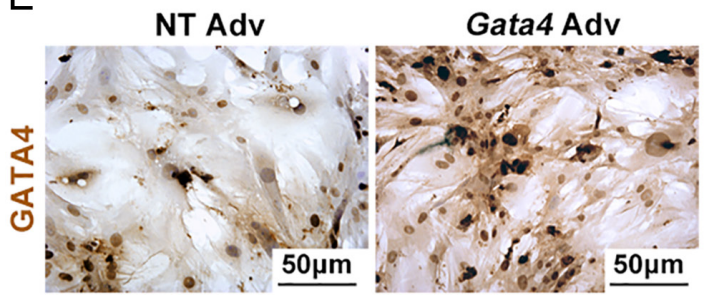

B
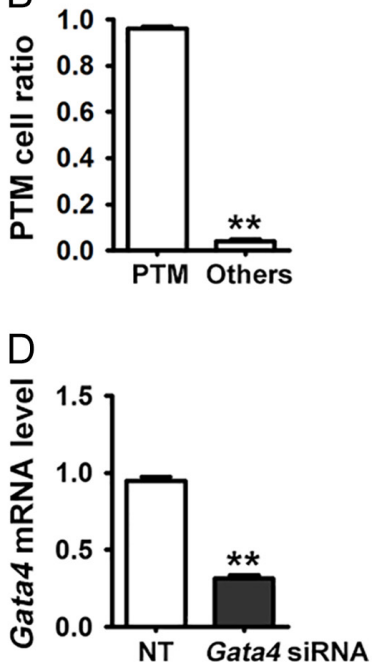

$\mathrm{F}$

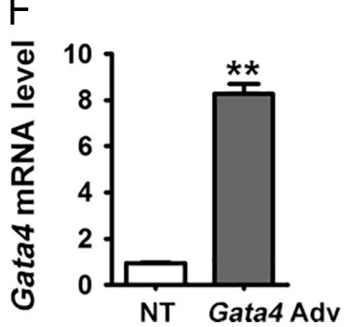

Figure 2 PTM cell isolation and alternation of GATA4 expression. (A) Representative image of isolated cells staining with a PTM cell marker $\alpha$-SMA (red signals). Nuclei were stained with DAPI. Scale bar, $10 \mu \mathrm{m}$. (B) Histogram illustrating the purity of isolated PTM cells, indicated by the percentage of $\alpha$-SMA-positive cells. (C)

Immunocytochemistry staining of GATA4 (brown signals) in Gata4 siRNA- and nontargeting siRNA-transfected PTM cells. Scale bar, $50 \mu \mathrm{m}$. (D) Relative mRNA level of Gata4 in Gata4 siRNA- and nontargeting siRNA-transfected PTM cells. (E) Cell staining of GATA4 in Gata4 adenovirus- and control adenovirus-infected PTM cells. Scale bar, $50 \mu \mathrm{m}$. (F) Altered mRNA level of Gata4 in PTM cells after Gata4 adenovirus infection. In $\mathrm{B}, \mathrm{D}, \mathrm{F}$, data are presented as the mean \pm S.E.M. ** indicates $P<0.01$ by Student's $t$ test.
GATA4 expression in PTM cells, respectively. The morphology of PTM cells was normal and their viability was unaffected after transfection (Supplementary Fig. 1). Immunocytochemistry staining showed markedly reduced GATA4 expression in Gata4 siRNA-treated cells (Fig. 2C) and increased expression after Gata4 adenovirus infection (Fig. 2E). Gata4 mRNA level was reduced by approximately $60 \%$ in cells treated with Gata4 siRNA vs nontargeting siRNA-treated cells by qRTPCR analysis (Fig. 2D). Conversely, Gata4 adenovirus infection significantly increased the mRNA expression of Gata4 (>8-fold) (Fig. 2F).

\section{Negative regulation of PTM cell contraction by GATA4}

Given that testicular PTM cells possess smooth musclelike characteristics and GATA4 is well known to determine the contractile ability of cardiomyocytes (leda et al. 2010, Aries et al. 2014), we sought to assess the regulatory role of GATA4 on testicular PTM cell contraction. Accordingly, a collagen gel contraction assay was applied to PTM cells that were pretreated with Gata4 siRNA, Gata4 adenovirus or their nontargeting controls. As an evaluation index, the contraction area was calculated after the 2-day observation cycle. The morphology of PTM cells in collagen gel appeared normal and undistinguishable among groups (Supplementary Fig. 1). We found that siRNA knockdown of GATA4 in
PTM cells significantly increased the contractile activity of PTM cells (Fig. 3A and C). By contrast, adenovirus overexpression of GATA4 in PTM cells resulted in a $42 \%$ decrease in contractile activity of PTM cells, as the contraction area was significantly reduced (Fig. 3B and C). Furthermore, we found that Gata4 siRNA-treated PTM cells showed obviously higher expression of $\alpha-S M A$ and more pronounced stress fibers than nontargeting controls and Gata4 adenovirus-treated PTM cells (Fig. 3C). Collectively, these data suggest that GATA4 is a negative regulator of contractility in mouse PTM cells.

\section{Changes of gene expression profiles in PTM cells influenced by GATA4}

To gain mechanistic insight into the negative regulation of PTM cell contraction by transcription factor GATA4, we performed RNA sequencing of Gata4 siRNA-treated, Gata4 adenovirus-treated, and their nontargeting control PTM cells. The expression levels of 91 genes were significantly increased (fold change (G4_Adv/NT_Adv) $\geq 2, P$ value $<0.05$ ) in Gata4 adenovirus-treated PTM cells; meanwhile, they were significantly downregulated (fold change (G4_siRNA/NT_siRNA) $\leq 0.5, \quad P$ value $<0.05$ ) in Gata4 siRNA-transfected PTM cells. A second class of 32 genes was negatively regulated by GATA4 in PTM cells (Fig. 4A). Cluster analysis revealed that the top four enriched pathways were ion channels (Fig. 4A and 
A

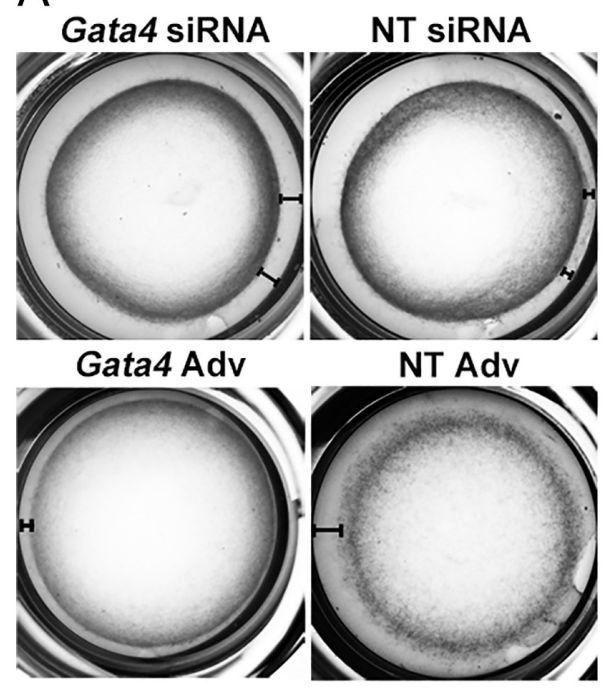

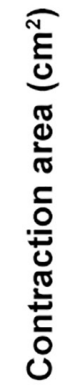

B

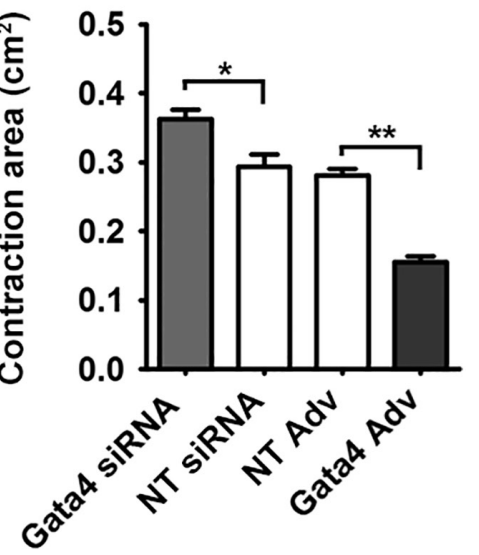

C $\alpha-S M A$
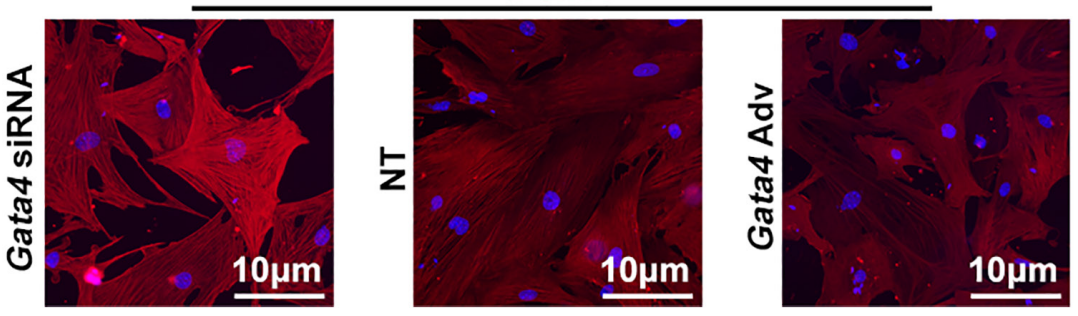

Figure 3 Negative regulation of PTM cell contraction by GATA4. (A) Collagen contractility assay in PTM cells transfected with Gata4 siRNA or Gata4 adenovirus or their nontargeting controls for 2 days. (B) Quantitative data showing the contraction area $\left(\mathrm{cm}^{2}\right)$ in Gata4 siRNA-, Gata4 adenovirus- and their control-treated PTM cells. Data are presented as the mean \pm S.E.M. *indicates $P<0.05$, ** indicates $P<0.01$ by Student's $t$ test. (C) Immunofluorescence images showing the distribution of $\alpha$-SMA in treated PTM cells. $\alpha$-SMA filaments organized in strongly labeled stress fibers after Gata4 silencing. Scale bar, $10 \mu \mathrm{m}$.
B), smooth muscle function (Fig. 4A and C), cytokines and chemokines (Fig. 4A and D), and cytoskeleton, adhesion and extracellular matrix (Fig. 4A and E).

\section{GATA4 regulates genes implicated in ion channels and smooth muscle contraction}

We hypothesize that genes implicated in ion channels $(n=11)$ and smooth muscle function $(n=15)$ are regulated by GATA4 and their dysregulation may contribute to the attenuated contractile ability of Gata4 adenovirus-treated PTM cells. Consistent with RNA sequencing data, the mRNA levels of genes linked to ion channels, such as Kcnk12, Kcnq5, Atpla3 were significantly upregulated in Gata4 adenovirus-treated PTM cells (Fig. 5A, B and C), while Nalcn was negatively regulated by GATA4 as revealed by qRT-PCR (Fig. 5D). Furthermore, the mRNA levels of Nppb and Gpr4, two quiescence factors of contraction, were significantly elevated after Gata4 adenovirus infection (Fig. 5E and F). Notably, GATA4 overexpression significantly attenuated mRNA levels of two well-known stimulators of PTM cell contraction, including Ednrb (encoding for endothelin receptor) and Agt (encoding for angiotensinogen) (Fig. 5G and $\mathrm{H}$ ). In agreement with transcriptome and qRT-PCR data, we found that natriuretic peptide type $B$ (NPPB) content was significantly upregulated after
Gata4 adenovirus treatment in both PTM cells and their culture supernatant (Fig. 5I). More importantly, the addition of $100 \mu \mathrm{M}$ NPPB could abolish the promoting effect of Gata4 siRNA on testicular PTM cell contraction (Fig. 5J). Collectively, the inhibitory action of GATA4 on PTM cell contraction is mediated at least partly by regulating genes belonging to ion channels and smooth muscle contraction signaling (e.g. Nppb) (Fig. 5K).

\section{Discussion}

GATA4 is expressed in several testicular somatic cell populations (Sertoli cells, Leydig cells and PTM cells) that play distinct roles in spermatogenesis (Bielinska et al. 2007, Mazaud Guittot et al. 2007, Penny et al. 2017). We and peers have revealed that GATA4 in Sertoli cells is essential for establishment and maintenance of SSC pool (Chen et al. 2015), while GATA4 regulates steroidogenesis and glycolysis in Leydig cells (Schrade et al. 2015). Here, we aimed to investigate the role of GATA4 in PTM cells and found that PTM cell contraction was negatively controlled by GATA4 partly by regulating genes belonging to ion channels and smooth muscle contraction signaling (e.g. Nppb).

So far, four agonists (endothelin, angiotensin II, platelet-derived growth factor, prostaglandin $\mathrm{F} 2 \alpha$ ) have been reported to stimulate testicular PTM cell 
A

Differentially expressed genes

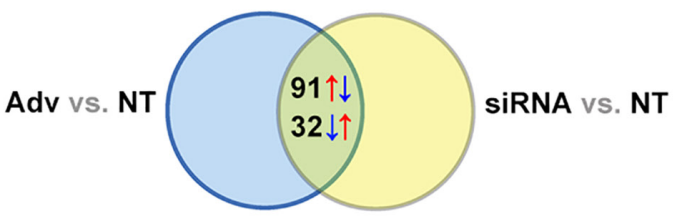

\begin{tabular}{|l|l|}
\hline Ion Channels & $n=11$ \\
\hline Smooth muscle function & $n=15$ \\
\hline Cytokines and chemokines & $n=24$ \\
\hline Cytoskeleton, adhesion, and ECM & $n=14$ \\
\hline
\end{tabular}

B

\begin{tabular}{|c|c|c|c|c|}
\hline & Adv & NT & siRNA & \\
\hline Kcnk12 & 4.4 & 1.0 & 0.2 & $\mathrm{~K}^{+}$channel \\
\hline Kcnq5 & 3.7 & 1.1 & 0.2 & $\mathrm{~K}^{+}$channel \\
\hline Atp1a3 & 3.5 & 1.2 & 0.5 & $\mathrm{Na}^{+} / \mathrm{K}^{+}-\mathrm{ATPases}$ \\
\hline Bspry & 2.9 & 0.9 & 0.4 & $\mathrm{Ca}^{2+}$ transport \\
\hline Slco4a1 & 2.9 & 1.2 & 0.5 & Anion transporter \\
\hline Rnd1 & 2.1 & 1.2 & 0.3 & $\mathrm{Ca}^{2+}$ sensitization \\
\hline SIc8a1 & 0.5 & 1.1 & 2.2 & $\mathrm{Na}^{+} / \mathrm{Ca}^{2+}$ exchanger \\
\hline Vstm4 & 0.5 & 0.9 & 2.4 & $\mathrm{Ca}^{2+}$ channel \\
\hline P2rx6 & 0.4 & 1.5 & 3.1 & ATP-gated ion channel \\
\hline Nalcn & 0.4 & 1.2 & 2.8 & $\mathrm{Ca}^{2+}$ channel \\
\hline Kcnma1 & 0.4 & 1.3 & 2.8 & $\mathrm{~K}^{+}$channel \\
\hline
\end{tabular}

C

\begin{tabular}{|c|c|c|c|c|}
\hline & \multirow[t]{2}{*}{11.1} & \multirow{2}{*}{\multicolumn{2}{|c|}{\begin{tabular}{|l|l|}
1.4 & 0.1 \\
1.2 & 0.2 \\
\end{tabular}}} & Quiescence of contraction \\
\hline & & 1.2 & & Myokine of SM \\
\hline & 2.9 & 0.9 & 0.2 & Proliferation and ROS of SM \\
\hline $\begin{array}{r}\text { Npp } \\
\text { Olr } \\
\text { Gpr }\end{array}$ & 2.9 & 0.9 & 0.3 & Binding of Agt receptor \\
\hline \multirow{2}{*}{$\begin{array}{l}\text { Htr1b } \\
\text { Ptas2 }\end{array}$} & 2.9 & 1.3 & 0.1 & SM contraction \\
\hline & 2.7 & 1.1 & 0.2 & PM Contractile \\
\hline \multirow{2}{*}{$\begin{array}{c}\text { Chrna7 } \\
\text { Prokr2 }\end{array}$} & 2.7 & 1.2 & 0.4 & Alleviates Agt function \\
\hline & 2.5 & 1.1 & 0.2 & SM Contractile \\
\hline \multirow{2}{*}{$\begin{array}{c}\text { Atf3 } \\
\text { Ereg }\end{array}$} & 2.5 & 1.0 & 0.3 & TFs regulated by ANG2 \\
\hline & 2.4 & 0.9 & 0.5 & ANG2, EDN1-induced mitogen \\
\hline \multirow{2}{*}{$\begin{array}{r}\text { Tbxa2r } \\
\text { Ace }\end{array}$} & 0.5 & 1.2 & 2.2 & Txa2-induced contraction \\
\hline & 0.5 & 1.1 & 3.7 & ANG1-converting enzyme \\
\hline \multirow{2}{*}{\begin{tabular}{|r|} 
Ednrb \\
Agt \\
\end{tabular}} & 0.3 & 1.8 & 3.2 & EDN1 receptor, PM contraction \\
\hline & 0.3 & 1.2 & 13.3 & ANG2, PM contraction \\
\hline Tmem204 & 0.5 & 1.4 & 8.2 & SM differentiation \\
\hline
\end{tabular}

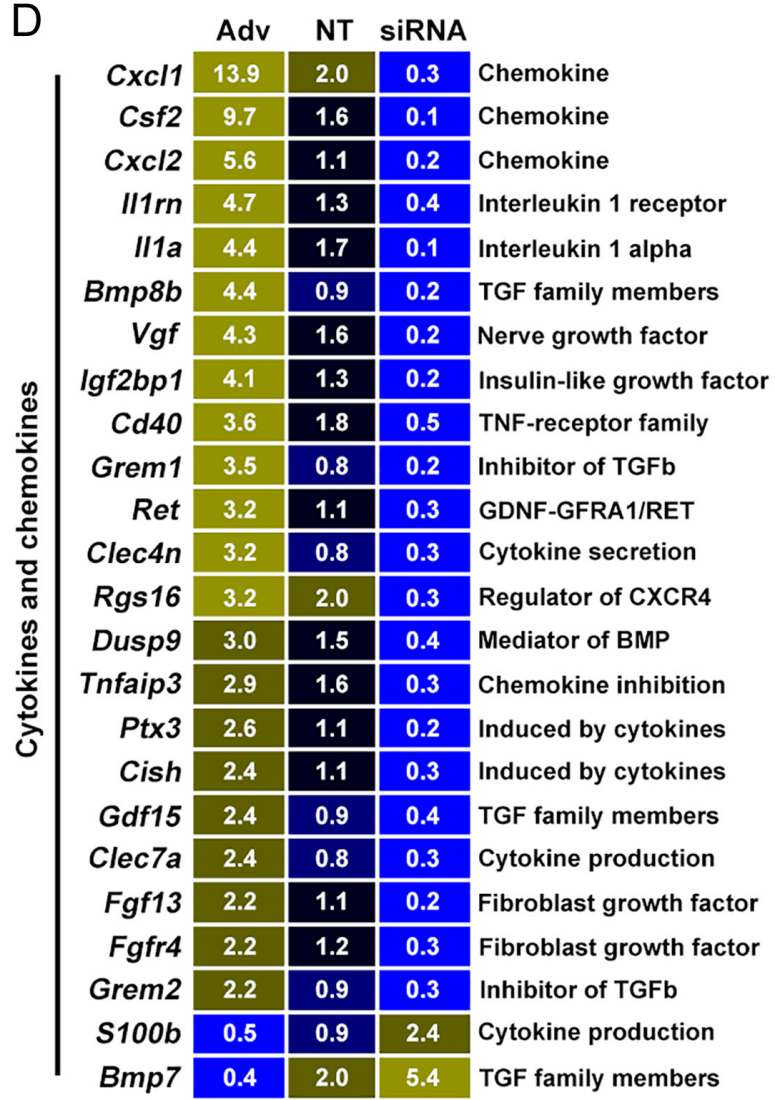

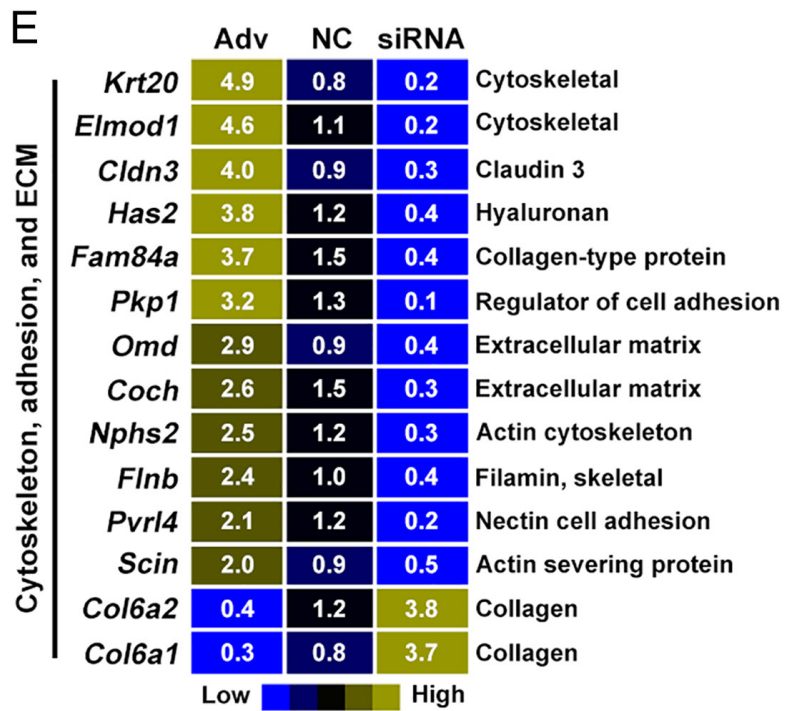

Figure 4 Gene expression profile of Gata4-silenced and -overexpressed PTM cells. (A) RNA sequencing discovering 91 GATA4-positively regulated genes and 32 genes that are negatively regulated by GATA4 in PTM cells. Table of biologic processes enriched in differentially expressed genes (KEGG analysis). (B, C, D and E) Expression levels (FPKM values) of selected gene sets, which are displayed with activities of ion channels (B), smooth muscle function (C), cytokines and chemokines (D), and cytoskeleton, adhesion and ECM (E) in Gata4 siRNA-, Gata4 adenovirus- and control-treated PTM cells. Red frames indicate genes that were further confirmed by qRT-PCR.

contraction (Tripiciano et al. 1998, Romano et al. 2006, 2007, Welter et al. 2014). Endothelin (also known as EDN1 or ET-1) has been shown to be produced by Sertoli cells and to bind EDNRB, a high-affinity receptor on
PTM cells, thus stimulating second messenger cascades and contractile response (Fantoni et al. 1993, Filippini et al. 1993, Romano et al. 2007). Our study suggests that Ednrb is repressed by GATA4 in PTM cells; thus, 

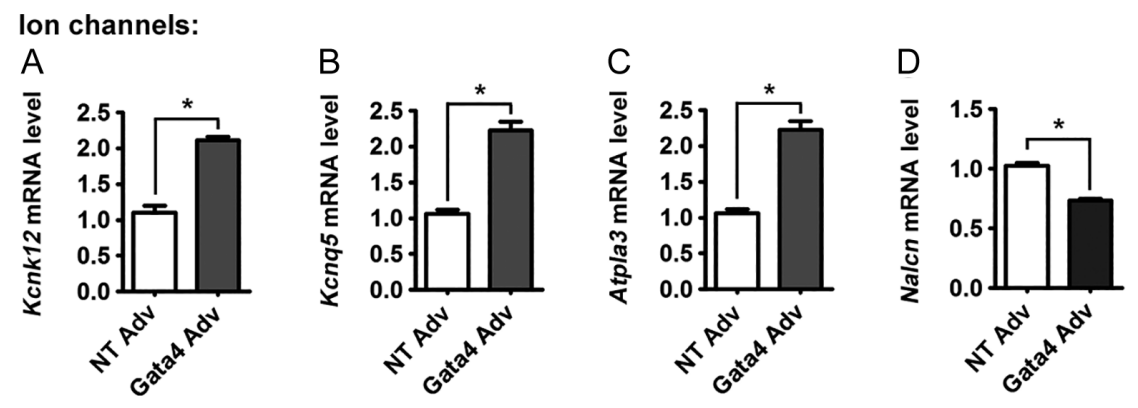

\section{Smooth muscle contraction:}

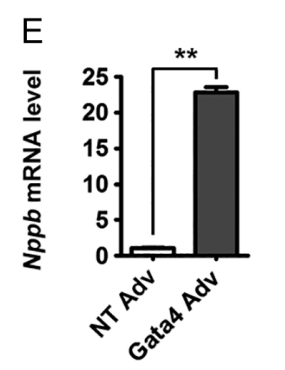

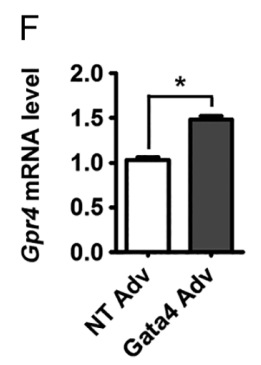
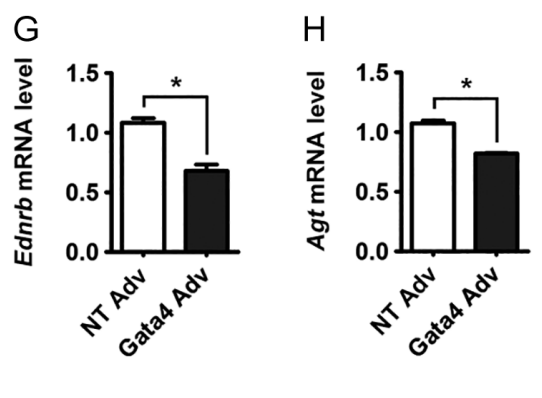

$\mathrm{K}$
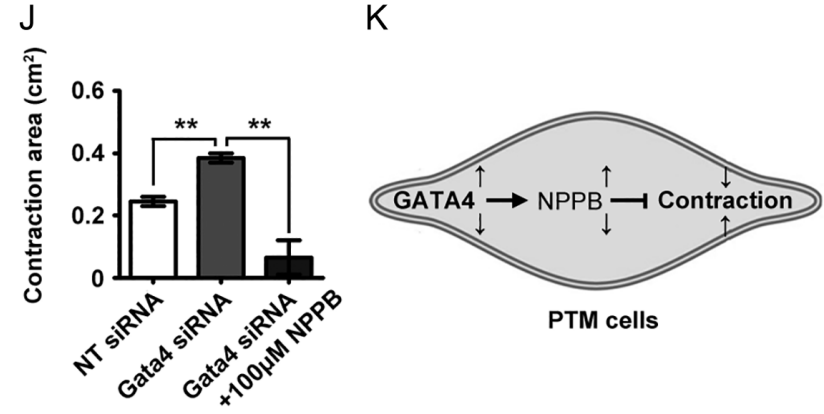

Figure 5 Dysregulation of genes implicated in ion channels and smooth muscle contraction in Gata4-overexpressed PTM cells. (A, B, C and D) Differential expression of genes belonging to ion channels, such as Kcnk 12 (A), Kcnq5 (B), Atpla3 (C) and Nalcn (D) between Gata4 adenovirus- and controltreated PTM cells. (E, F, G and H) The mRNA levels of genes implicated in smooth muscle contraction, such as Nppb (E), Gpr4 (F), Ednrb (G) and Agt $(\mathrm{H})$ in Gata4-overexpressed and control groups. (I) Analysis of the content of NPPB $(\mathrm{pg} / \mathrm{mL})$ in Gata4 adenovirus- or nontargeting control-transfected PTM cells and their culture media by ELISA assay. $M$, culture media; C, cells. (J) Quantitative data showing the contraction area $\left(\mathrm{cm}^{2}\right)$ in control-, Gata4 siRNA alone-, Gata4 siRNA plus $100 \mu \mathrm{M}$ NPPB-treated PTM cells. Data are presented as the mean \pm S.E.M. ${ }^{*}$ indicates $P<0.05$, **indicates $P<0.01$ by Student's $t$ test. (K) Hypothetical and simplified model of critical factors (e.g. NPPB) involved in the regulation of PTM contraction by GATA4. the EDN1 (ligand)-EDNRB (receptor) signaling may be attenuated after GATA4 overexpression. Based on the RNA sequencing and qRT-PCR data, we suggest that GATA4 negatively regulates PTM cell contraction likely via both depressing the expression of Agt (encoding for angiotensinogen) and Ace (encoding for angiotensinconverting enzyme) and upregulating the level of Gpr4 that may be a reductor of angiotensin receptor affinity (Sanada et al. 2016, Sun et al. 2016). Angiotensin I (ANGI) is formed by the action of renin on AGT, and it is further converted to ANGIl through removal of two C-terminal residues by the enzyme ACE (Welter et al. 2014). Notably, forced GATA4 expression upregulates both the mRNA and protein level of natriuretic peptide type B (NPPB), an agonist of smooth muscle cell contraction (Carvajal 2014, Orlandi et al. 2015). Addition of NPPB could abolish the promoting effect of Gata4 silencing on PTM cell contraction, indicating NPPB is also an inhibitor for PTM cell contraction and involved in the regulation of PTM contractility by GATA4. Another GATA4 positively regulated gene that attracts our attention is pentraxin 3 (Ptx3). PTX3 has been identified as a major product of human PTM cells by secretome analysis (Flenkenthaler et al. 2014). A recent study further suggest that biglycan
(BGN) serves as a ligand of toll-like receptor 2 (TLR2) and increases the protein expression and secretion of pentraxin 3 (PTX3) in PTM cells (Mayer et al. 2016). However, the role of PTX3 in the testis and its relationship with transcription factor GATA4 and PTM cell contraction needs further investigation.

Studies on roles of ion channels in testicular PTM contraction do not exist. However, there is close relationship between smooth muscle cell contraction and ion channels, because mobilization of intracellular ions plays critical roles in initiating and modulating the intensity and duration of contraction response (Hakonarson \& Grunstein 1998). Our high-throughput screening reveals that eleven genes belonging to ion channels are potentially regulated by GATA4, of which Kcnq5, Rnd1, Nalcn and Kcnma1 are suggested to regulate smooth muscle cell contraction (Loirand et al. 1999, Jepps et al. 2009, Reinl et al. 2015, Chen et al. 2016b, Mani et al. 2016). As testicular PTM cells are smooth muscle-like cells, further studies investigating the role of these ion channel-related genes on PTM cell contraction will be of great interest.

Interestingly, bioinformatics analysis and literature search of differentially expressed genes further revealed 
that approximately $24 \%$ (17 of 72 ) of GATA4-regulated genes could be linked to EGF-EGF receptor (EGFR) pathway. The altered expression of these 17 genes was further confirmed by qRT-PCR (data not shown). EGF could be modified by a couple of GATA4-regulated genes, including Nppb, Grem1, Bmp8b, Omd, Ptgs2 and Atf3. EGFR could be regulated by Ubash3b, Ereg, Reps2, Fgfr4 and Gprc5a. Downstream signaling of EGF-EGFR pathway, such as RAS/RAF/MEK/ERK, STAT and PI3K/AKT/mTOR, could be targeted by Elmod1, Olr1, Cish, Pvrl4, Atp1a3 and Igf2b1. Collectively, our preliminary results suggest that the EGF-EGFR pathway may be involved in downstream signaling of GATA4 in PTM cells and is potential critical for PTM cell contraction.

Two previous studies investigated the roles of $A R$ and GDNF in PTM cells and spermatogenesis using flox mice and Myh11-Cre strain (Welsh et al. 2009, Chen et al. 2016a). It is essential to further observe the in vivo role of Gata4 in PTM cells by generating Gata4-conditional knockout mouse models. However, we found embryonic lethality in Gata4floxflox, Myh11-Cre mice. Accordingly, screening of PTM cell-specific markers should be of great concern, because Myh11-Cre is expressed in all kinds of smooth muscle cells, including, but not limited to PTM cells (Chen \& Liu 2016).

\section{Supplementary data}

This is linked to the online version of the paper at https://doi.org/10.1530/REP-18-0148.

\section{Declaration of interest}

The authors declare that there is no conflict of interest that could be perceived as prejudicing the impartiality of the research reported.

\section{Funding}

This work was sponsored by the National Nature Science Foundation of China (grant no. 31471352 to Y-X Liu; 31501198 to S-R Chen); the Young Elite Scientists Sponsorship Program by CAST (grant no. YESS20160118 to S-R Chen); the Academician Workstation Support (Changsha, Shandong, and Shenyang to Y-X Liu) and the Clinical Capability Construction Project for Liaoning Provincial Hospitals (LNCCC-D50-2015, LNCCC-C09-2015 to Y-X Liu).

\section{References}

Aries A, Whitcomb J, Shao W, Komati H, Saleh M \& Nemer M 2014 Caspase-1 cleavage of transcription factor GATA4 and regulation of cardiac cell fate. Cell Death and Disease 5 e1566. (https://doi. org/10.1038/cddis.2014.524)

Bergeron F, Nadeau G \& Viger RS 2015 GATA4 knockdown in MA-10 Leydig cells identifies multiple target genes in the steroidogenic pathway. Reproduction 149 245-257. (https://doi.org/10.1530/REP-14-0369)
Bielinska M, Seehra A, Toppari J, Heikinheimo M \& Wilson DB 2007 GATA4 is required for sex steroidogenic cell development in the fetal mouse. Developmental Dynamics 236 203-213. (https://doi.org/10.1002/ dvdy.21004)

Carvajal JA 2014 The role of brain natriuretic peptide in maintaining myometrial quiescence during pregnancy. Experimental Physiology 99 489-494. (https://doi.org/10.1113/expphysiol.2013.077446)

Chen SR \& Liu YX 2015 Regulation of spermatogonial stem cell self-renewal and spermatocyte meiosis by Sertoli cell signaling. Reproduction 149 R159-R167. (https://doi.org/10.1530/REP-14-0481)

Chen SR \& Liu YX 2016 Myh11-Cre is not limited to peritubular myoid cells and interaction between Sertoli and peritubular myoid cells needs investigation. PNAS 113 E2352. (https://doi.org/10.1073/ pnas.1602873113)

Chen SR, Chen M, Wang XN, Zhang J, Wen Q, Ji SY, Zheng QS, Gao F \& Liu YX 2013 The Wilms tumor gene, Wt1, maintains testicular cord integrity by regulating the expression of Col4a1 and Col4a2. Biology of Reproduction 88 56. (https://doi.org/10.1095/biolreprod.112.105379)

Chen LY, Brown PR, Willis WB \& Eddy EM 2014 Peritubular myoid cells participate in male mouse spermatogonial stem cell maintenance. Endocrinology 155 4964-4974. (https://doi.org/10.1210/en.2014-1406)

Chen SR, Tang JX, Cheng JM, Li J, Jin C, Li XY, Deng SL, Zhang Y, Wang XX \& Liu YX 2015 Loss of Gata4 in Sertoli cells impairs the spermatogonial stem cell niche and causes germ cell exhaustion by attenuating chemokine signaling. Oncotarget 6 37012-37027. (https:// doi.org/10.18632/oncotarget.6115)

Chen LY, Willis WD \& Eddy EM 2016a Targeting the Gdnf Gene in peritubular myoid cells disrupts undifferentiated spermatogonial cell development. PNAS 113 1829-1834. (https://doi.org/10.1073/ pnas.1517994113)

Chen M, Li J, Jiang F, Fu J, Xia X, Du J, Hu M, Huang J \& Shen B 2016 b Orai1 forms a signal complex with BKCa channel in mesenteric artery smooth muscle cells. Physiological Reports 4 e12682. (https://doi.org/ 10.14814/phy2.12682)

Chen SR, Batool A, Wang YQ, Hao XX, Chang CS, Cheng CY \& Liu YX 2016c The control of male fertility by spermatid-specific factors: searching for contraceptive targets from spermatozoon's head to tail. Cell Death and Disease 7 e2472. (https://doi.org/10.1038/cddis.2016.344)

DeFalco T, Potter SJ, Williams AV, Waller B, Kan MJ \& Capel B 2015 Macrophages contribute to the spermatogonial niche in the adult testis. Cell Reports 12 1107-1119. (https://doi.org/10.1016/j. celrep.2015.07.015)

Fantoni G, Morris PL, Forti G, Vannelli GB, Orlando C, Barni T, Sestini R, Danza G \& Maggi M 1993 Endothelin-1: a new autocrine/paracrine factor in rat testis. American Journal of Physiology 265 E267-E274. (https://doi.org/10.1152/ajpendo.1993.265.2.E267)

Fehlmann T, Reinheimer S, Geng C, Su X, Drmanac S, Alexeev A, Zhang C, Backes C, Ludwig N, Hart M et al. 2016 cPAS-based sequencing on the BGISEQ-500 to explore small non-coding RNAs. Clinical Epigenetics 8 123. (https://doi.org/10.1186/s13148-016-0287-1)

Filippini A, Tripiciano A, Palombi F, Teti A, Paniccia R, Stefanini M \& Ziparo E 1993 Rat testicular myoid cells respond to endothelin: characterization of binding and signal transduction pathway. Endocrinology 133 1789-1796. (https://doi.org/10.1210/endo.133.4.8404621)

Flenkenthaler F, Windschüttl S, Fröhlich T, Schwarzer JU, Mayerhofer A \& Arnold GJ 2014 Secretome analysis of testicular peritubular cells: a window into the human testicular microenvironment and the speramtogonial stem cell niche in man. Journal of Proteome Research 13 1259-1269. (https://doi.org/10.1021/pr400769z)

Hakonarson H \& Grunstein MM 1998 Regulation of second messengers associated with airway smooth muscle contraction and relaxation. American Journal of Respiratory and Critical Care Medicine 158 S115S122. (https://doi.org/10.1164/ajrccm.158.supplement_2.13tac700)

leda M, Fu JD, Delgado-Olguin P, Vedantham V, Hayashi Y, Bruneau BG \& Srivastava D 2010 Direct reprogramming of fibroblasts into functional cardiomyocytes by defined factors. Cell 142 375-386. (https://doi. org/10.1016/j.cell.2010.07.002)

Jepps TA, Greenwood IA, Moffatt JD, Sanders KM \& Ohya S 2009 Molecular and functional characterization of $\mathrm{Kv} 7 \mathrm{~K}+$ channel in murine gastrointestinal smooth muscles. American Journal of Physiology: Gastrointestinal and Liver Physiology 297 G107-G115. (https://doi. org/10.1152/ajpgi.00057.2009) 
Li XX, Chen SR, Shen B, Yang JL, Ji SY, Wen Q, Zheng QS, Li L, Zhang J, Hu ZY et al. 2013 The heat-induced reversible change in the bloodtestis barrier (BTB) is regulated by the androgen receptor (AR) via the partitioning-defective protein (Par) polarity complex in the mouse. Biology of Reproduction 89 12. (https://doi.org/10.1095/biolreprod.113. 109405)

Loirand G, Cario-Toumaniantz C, Chardin P \& Pacaud P 1999 The Rhorelated protein Rnd1 inhibits $\mathrm{Ca} 2+$ sensitization of rat smooth muscle. Journal of Physiology 516 825-834. (https://doi.org/10.1111/j.14697793.1999.0825u.x)

Mani BK, Robakowski C, Brueggemann LI, Cribbs LL, Tripathi A, Majetschak M \& Byron KL 2016 Kv7.5 Potassium channel subunits are the primary targets for PKA-dependent enhancement of vascular smooth muscle Kv7 currents. Molecular Pharmacology 89 323-334. (https://doi. org/10.1124/mol.115.101758)

Mayer C, Adam M, Glashauser L, Dietrich K, Schwarzer JU, Köhn FM, Strauss L, Welter H, Poutanen M \& Mayerhofer A 2016 Sterile inflammation as a factor in human male infertility: involvement of Toll like receptor 2, biglycan and peritubular cells. Scientific Reports 6 37128. (https://doi.org/10.1038/srep37128)

Mayerhofer A 2013 Human testicular peritubular cells: more than meets the eye. Reproduction 145 R107-R116. (https://doi.org/10.1530/REP12-0497)

Mazaud Guittot S, Tetu A, Legault E, Pilon N, Silversides DW \& Viger RS 2007 The proximal Gata4 promoter directs reporter gene expression to sertoli cells during mouse gonadal development. Biology of Reproduction 76 85-95. (https://doi.org/10.1095/biolreprod.106.055137)

Oatley JM, Oatley MJ, Avarbock MR, Tobias JW \& Brinster RL 2009 Colony stimulating factor 1 is an extrinsic stimulator of mouse spermatogonial stem cell self-renewal. Development 136 1191-1199. (https://doi. org/10.1242/dev.032243)

Orlandi A, Calzetta L, Doldo E, Tarquini C, Matera MG \& Passeri D 2015 Brain natriuretic peptide modulates calcium homeostasis and epidermal growth factor receptor gene signalling in asthmatic airways smooth muscle cells. Pulmonary Pharmacology and Therapeutics 31 51-54. (https://doi.org/10.1016/j.pupt.2015.02.005)

Penny GM, Cochran RB, Pihlajoki M, Kyronlahti A, Schrade A, Hakkinen M, Toppari J, Heikinheimo M \& Wilson DB 2017 Probing GATA factor function in mouse Leydig cells via testicular injection of adenoviral vectors. Reproduction 154 455-467. (https://doi.org/10.1530/REP-170311)

Qian Y, Liu S, Guan Y, Pan H, Guan X, Qiu Z, Li L, Gao N, Zhao Y, Li X et al. 2013 Lgr4-mediated Wnt/beta-catenin signaling in peritubular myoid cells is essential for spermatogenesis. Development $\mathbf{1 4 0}$ 1751-1761. (https://doi.org/10.1242/dev.093641)

Rebourcet D, O'Shaughnessy PJ, Pitetti JL, Monteiro A, O'Hara L, Milne L, Tsai YT, Cruickshanks L, Riethmacher D, Guillou F et al. 2014 Sertol cells control peritubular myoid cell fate and support adult Leydig cell development in the prepubertal testis. Development 141 2139-2149. (https://doi.org/10.1242/dev.107029)

Reinl EL, Cabeza R, Gregory IA, Cahill AG \& England SK 2015 Sodium leak channel, non-selective contributes to the leak current in human myometrial smooth muscle cells from pregnant women. Molecular Human Reproduction 21 816-824. (https://doi.org/10.1093/molehr/ gav038)

Romano F, Chiarenza C, Palombi F, Filippini A, Padula F, Ziparo E \& De Cesaris P 2006 Platelet-derived growth factor-BB-induced hypertrophy of peritubular smooth muscle cells is mediated by activation of p38
MAP-kinase and of Rho-kinase. Journal of Cellular Physiology 207 123-131. (https://doi.org/10.1002/jcp.20554)

Romano F, Gambara G, De Cesaris P, Ziparo E, Palombi F \& Filippini A 2007 Endothelin induces functional hypertrophy of peritubular smooth muscle cells. Journal of Cellular Physiology 212 264-273. (https://doi. org/10.1002/jcp.21028)

Sanada H, Yoneda M, Yatabe J, Williams SM, Bartlett J, White MJ, Cordon LN, Felder RA, Risner GM, Armando I et al. 2016 Common variants of the G protein-coupled receptor type 4 are associated with human essential hypertension and predict the blood pressure response to angiotensin receptor blockade. Pharmacogenomics Journal 16 3-9. (https://doi.org/10.1038/tpj.2015.6)

Schell C, Albrecht M, Spillner S, Mayer C, Kunz L, Kohn FM, Schwarzer U \& Mayerhofer A 2010 15-Deoxy-delta 12-14-prostaglandin-J2 induces hypertrophy and loss of contractility in human testicular peritubular cells: implications for human male fertility. Endocrinology 151 1257-1268. (https://doi.org/10.1210/en.2009-1325)

Schrade A, Kyronlahti A, Akinrinade O, Pihlajoki M, Hakkinen $M$, Fischer S, Alastalo TP, Velagapudi V, Toppari J, Wilson DB et al. 2015 GATA4 is a key regulator of steroidogenesis and glycolysis in mouse Leydig cells. Endocrinology 156 1860-1872. (https://doi.org/10.1210/ en.2014-1931)

Schrade A, Kyronlahti A, Akinrinade O, Pihlajoki M, Fischer S, Rodriguez VM, Otte K, Velagapudi V, Toppari J, Wilson DB et al. 2016 GATA4 regulates blood-testis barrier function and lactate metabolism in mouse sertoli cells. Endocrinology 157 2416-2431. (https://doi. org/10.1210/en.2015-1927)

Sun X, Tommasi E, Molina D, Sah R, Bronihan KB, Diz D \& Petrovic S 2016 Deletion of proton-sensing receptor GPR4 associates with lower blood pressure and lower binding of angiotensin II receptor in SFO. American Journal of Physiology: Renal Physiology 311 F1260-F1266. (https://doi. org/10.1152/ajprenal.00410.2016)

Tripiciano A, Filippini A, Ballarini F \& Palombi F 1998 Contractile response of peritubular myoid cells to prostaglandin F2alpha. Molecular and Cellular Endocrinology 138 143-150. (https://doi.org/10.1016/S03037207(98)00010-0)

Welsh M, Saunders PT, Atanassova N, Sharpe RM \& Smith LB 2009 Androgen action via testicular peritubular myoid cells is essential for male fertility. FASEB Journal 23 4218-4230. (https://doi.org/10.1096/ fj.09-138347)

Welter H, Kampfer C, Lauf S, Feil R, Schwarzer JU, Kohn FM \& Mayerhofer A 2013 Partial loss of contractile marker proteins in human testicular peritubular cells in infertility patients. Andrology $1318-324$. (https://doi.org/10.1111/j.2047-2927.2012.00030.x)

Welter H, Huber A, Lauf S, Einwang D, Mayer C, Schwarzer JU, Kohn FM \& Mayerhofer A 2014 Angiotensin II regulates testicular peritubular cell function via AT1 receptor: a specific situation in male infertility. Molecular and Cellular Endocrinology 393 171-178. (https://doi. org/10.1016/j.mce.2014.06.011)

Received 16 March 2018

First decision 3 April 2018

Revised manuscript received 6 July 2018

Accepted 13 July 2018 